\title{
Reflexões sobre o conceito e a função da universidade pública
}

FRANKLIN LEOPOLDO E SILVA

\section{A motivação política da expansão do ensino superior privado: causas e conseqüências}

$\mathrm{N}$ UNCA É DEMAIS retornar à gênese dos fatos, para melhor discuti-los. Muito do que se discute atualmente acerca da universidade poderia ser mais bem focalizado se considerássemos determinadas continuidades, por vezes deliberadamente ocultadas sob a capa das novidades ilusórias e das emergências do presente. Desde que o Relatório Atcon diagnosticou o estrangulamento no canal de acesso à universidade, a preocupação dos governos que se sucederam durante a ditadura militar foi a ampliação de vagas sem que isto representasse um investimento significativo. A partir daí é que se firmou a argumentação de que o ensino privado superior cumpriria uma função complementar, tendo em vista a impossibilidade de o poder público arcar completamente com este ônus.

A entrada da iniciativa privada no ensino superior deu-se primeiramente por meio de uma ampliação das atividades que os empresários da educação já exerciam na esfera do ensino básico. Assim, a mesma mentalidade organizacional que fez expandir e consolidar as empresas de ensino de primeiro e segundo graus passou a reger as iniciativas privadas no ensino universitário, até porque se tratava dos mesmos grupos. A idéia era trazer a eficiência empresarial, já comprovada no ensino básico, para o ensino universitário e marcar, também neste nível, superioridade organizacional da empresa particular em relação à instituição pública.

Disto resultaram duas conseqüências de ordem propriamente política. Em primeiro lugar, a proliferação de escolas privadas de ensino superior (o CFE deferiu 759 solicitações entre 1968 e 1972) permitiu o acesso de vastas camadas da classe média ao ensino universitário, atendendo assim a uma expectativa que se vinha tornando cada vez maior. Em segundo lugar, o caráter próprio dessas organizações empresariais supunha naturalmente um perfil de curso superior significativamente distinto daquele dos cursos em instituições públicas. Os parâmetros de eficiência e lucratividade excluíam qualquer ideário pedagógico mais consistente, o que foi substituído pelo senso de oportunidade comercial na organização e venda de serviços segundo o critério da demanda. Este tipo de atitude compunha-se muito bem com o regime autoritário, que entendia a 
universidade como formadora de "recursos humanos" de acordo com a ideologia do desenvolvimento e da segurança nacionais.

Desta forma, a ditadura encontrou na expansão do ensino privado tanto um meio de se desonerar da responsabilidade educativa quanto um instrumento ideológico eficaz para a adaptação do alunado às regras de comportamento político (ou apolítico) vigentes. Há de se entender também que os parâmetros de lucratividade e eficiência repercutiam diretamente na questão da qualidade e do nível de ensino ministrado. A dependência da clientela para a sobrevivência econômica da empresa gerava naturalmente um nivelamento por baixo das exigências didáticas. Como este rebaixamento redundava num aumento visível do número de graduados em nível superior, isto também vinha ao encontro das expectativas do governo, na medida que constituía uma maneira de alimentar com ilusões e falsas esperanças os anseios de ascensão da classe média.

É preciso considerar como vivenciamos hoje as conseqüências desta idéia perversa de expansão e democratização do ensino superior. $\mathrm{O}$ conceito de eficiência organizacional como condição da atividade universitária está definitivamente implantado na instituição pública. Proliferam as análises que tentam diagnosticar todas as dificuldades enfrentadas pelas universidades públicas como derivadas de defeitos na gestão. Como a instituição pública é em geral mais complexa que a empresa de ensino privada, por ter de atender a expectativas mais amplas de atuação, o modelo econômico-pragmático de administração não pode se restringir naturalmente à gestão econômica, estendendo-se então à totalidade das atividades, que passam a se subordinar, em larga medida, às injunções gestionárias. A aplicação do modelo privatista a instituições que, pelo menos em tese, se caracterizam pela prioridade dos aspectos intelectuais e acadêmicos, gera as contradições que existem atualmente, mascaradas pela progressiva adaptacão do trabalho intelectual e acadêmico às novas exigências, o que passou a ser visto como condição de sobrevivência acadêmica e por isto foi introjetada por grande parcela do corpo docente, a ponto de se tornar a cada dia algo mais "natural", mas "racional" e mais "sensato".

Ora, as empresas de ensino superior, ao contrário das escolas confessionais, sempre condicionaram a eficiência de sua organização a uma independência do poder público. Em troca dos serviços prestados, que desoneram o governo de parte de suas responsabilidades pela educação, reivindicam com freqüência que este mesmo governo não interfira no modo como essas escolas se organizam, como organizam o ensino e principalmente nos critérios de fixação e reajuste de mensalidades. A razão é simples: dependendo exclusivamente do pagamento dos alunos para a sua sobrevivência, e não de verbas governamentais, a qualidade e extensão dos serviços prestados estão diretamente vinculados à autonomia na gerência dos custos, nomeadamente na captação das mensalidades. Assim, firmase a idéia - que até bem pouco tempo era diretriz de todas as escolas superiores 
não confessionais - de que uma organização de ensino deve viver do que cobra de sua clientela, administrando com a máxima eficiência estes recursos.

\section{Gratuidade, elitismo e necessidades sociais}

Esta ligação entre eficiência e inserção adequada no mercado parece exercer um certo fascínio sobre aqueles que se manifestam favoráveis à extinção da gratuidade. A idéia de que a eficiência anda de mãos dadas com recursos gerados a partir de captação no mercado, e de que o ensino é um produto que deve ser posto no regime de competição como todos os outros, se opõe à imagem da acomodação, do conservadorismo e da ineficiência das instituições que, contando com verbas públicas, não dependem de estratégias eficientes para sobreviver no mercado. Este argumento supõe a concepção de que o regime de competição seja a única forma de conduzir à eficiência. Se as instituições públicas adotarem eventualmente uma estratégia de extinção gradual da gratuidade, num processo pensado a médio prazo, em que a cobrança de taxas módicas conviveria com alguma subvenção pública, isto redundaria no oferecimento de ensino de qualidade a preços competitivos no mercado.

A este argumento, aparentemente fundado na necessidade de eficiência organizacional, junta-se outro, que tem a ver com uma concepção "mitigada" de ensino pago e que apela para a necessidade de "democratização" do ensino público superior. Consiste em propor que se cobrem taxas daqueles que podem pagar para, com tais recursos, financiar aqueles que realmente só poderiam estudar em condições de gratuidade. A objeção mais imediata ao aparente bom-senso desta proposta pode ser formulada examinando-se o que se entende por "democratização" e as causas pelas quais a universidade pública pode ser acusada de "elitismo". Democratização significa, neste contexto, que o acesso à universidade não dependa de condições sócio-econômicas e que os critérios de ingresso não favoreçam as pessoas que detêm situação sócio-econômica privilegiada. O que se pode constatar, até mesmo estatisticamente, é que a condição sócio-econômica parece representar papel decisivo no ingresso em várias carreiras, principalmente nas universidades públicas mais bem conceituadas.

A superioridade da situação sócio-econômica se traduz, neste caso, por melhores condições de preparo para o vestibular: bons colégios, o que no nosso contexto significa colégios e cursinhos caros, existindo aí o entrecruzamento do aluno melhor preparado com o aluno que dispõe de condições sócio-econômicas para atingir este nível. Sabe-se que nas carreiras menos competitivas a proporção de ingressantes oriundos de colégios públicos é maior. O que esta situação revela não é a substituição do mérito pela condição sócio-econômica, mas sim que aqueles que dispõem de meios estão mais aptos a cumprir os requisitos de mérito. Supondo a aceitação do critério do mérito como o mais adequado, é possível verificar que a discussão se situa muitas vezes num patamar inadequado. 
O desinteresse generalizado dos governos pela escola pública básica gerou a distância enorme que atualmente se constata entre o ensino básico e a universidade pública em termos de qualidade de ensino. Esta distância só tende a aumentar se persistirem, de um lado, o processo de deterioração do ensino básico público e, de outro, as exigências para o ingresso nas universidades públicas. Parece claro, diante disto, que a alternativa para que se diminua o "elitismo" não pode ser a adaptação da universidade à indigência do ensino básico, mas sim a recomposição da escola pública de primeiro e segundo graus. E esta é uma questão política porque tal recomposição dependeria de uma profunda revisão das prioridades que orientam a atuação dos governos.

Não se trata apenas de um problema de "reestruturação" interna das atividades de ensino, mas de uma opção política mais ampla, que considere a questão nos seus vários aspectos, o principal dos quais é o resgate da figura do professor da escola pública básica. O alcance das mudanças necessárias exige, pois, uma inflexão decidida num processo histórico de degradação do ensino, que parece ter sido assumido como irreversível. Assim, a situação que se configura como “elitista” tem raízes profundas fora da universidade, já que os colégios públicos não oferecem condições para que seus alunos possam competir em condições de igualdade. Como não é possível mudar a situação de competitividade, somente a recomposição da escola pública implicaria uma democratização das oportunidades. Vemos então que a "democratização da universidade" não é uma questão que possa ser resolvida somente pela universidade.

Não se pode também confundir democratização do acesso com atendimento a carências da sociedade, que na maioria das vezes existem como efeito de opções políticas mais amplas assumidas pelos governos. A idéia de que a universidade pública destina-se aos carentes é equivocada ou demagógica. Ela destinase a todos aqueles que cumprem os requisitos de ingresso. Ocorre que as universidades públicas mais conceituadas têm uma história caracterizada pela manutenção de um elevado padrão de ensino e de exigências, o que já está presente, pelo menos em parte, nos exames de ingresso. Essas exigências estão largamente distanciadas do preparo que o aluno do colégio público recebe. Juntando-se a isto o número cada vez mais elevado de postulantes, o resultado é o afunilamento que, na prática, se traduz nas diferenças sócio-econômicas. A universidade não resolve por si mesma e imediatamente as carências sociais, embora possa contribuir, na esfera que lhe é própria, para o encaminhamento de soluções. Está inscrita na própria idéia de autonomia universitária uma relação mediada com a sociedade.

A concepção de que a universidade deveria ter uma relação direta com as necessidades sociais é profundamente contrária à autonomia que deve caracterizar o ensino e a pesquisa. Com efeito, "necessidades sociais" permanece algo abstrato enquanto não for explicitado por alguma instância que as interprete na forma de 
prioridades, diretrizes e orientações que atendam efetivamente a tais necessidades. No plano das relações institucionais esta instância tende a ser o Estado e, na prática, os governos. Deste modo correr-se-ia o risco de inserir a universidade no ritmo das conjunturas políticas que se sucedem, o que equivaleria a um profundo desequilíbrio do trabalho universitário, o qual deve ser orientado por um núcleo permanente em que resida o ideário mais amplo e mais originário pelo qual a instituição se deveria pautar.

\section{Autonomia, caráter público e função social da universidade}

A que necessidades sociais responde o ensino superior privado? Certamente, àquelas que são filtradas pelo mercado. É esta correspondência imediatista à demanda que se reflete na organização empresarial das escolas particulares, e esta inserção direta no mercado constitui critério a que se submetem todos os aspectos da organização do ensino. Neste sentido, a expansão do ensino privado é conseqüência da visão do mercado como critério universal. Se isto estava confusamente embutido na opção dos governos da ditadura, agora trata-se de algo plenamente manifesto na vigência das escolhas neoliberais. Boa parcela das acusações de arcaísmo, corporativismo e ineficiência feitas à universidade pública visa, na verdade, ao distanciamento que ela, em grande parte, ainda mantém do mercado. E por não estar limitada pelas injunções do mercado é que a universidade pública pode cumprir o seu papel histórico e social de produção e disseminação do conhecimento, e também manter com a cultura uma relação intrínseca que se manifesta numa possibilidade de reflexão que foge aos moldes do compromisso imediatamente definido pelas pressões de demanda e de consumo.

É sabido que as universidades públicas que atingiram altos padrões de ensino e pesquisa foram aquelas que optaram pela valorização da dedicação exclusiva e pela pesquisa básica, isto é, exatamente aquelas que mantêm, em meio a todas as dificuldades, um grau elevado de independência com relação às injunções imediatas do mercado. E os obstáculos atualmente enfrentados para a manutenção destes requisitos refletem as pressões externas (e em grande parte já introjetadas) que a instituição vêm sofrendo.

Tais pressões, profundamente desintegradoras, tendem a anular a diferença entre instituição pública e organização empresarial, o que é uma conseqüência do processo de desmantelamento do espaço público, atualmente em curso. $\mathrm{Na}$ impossibilidade de examinar-se aqui as raízes históricas deste processo, que é mundial, interessa-nos analisar alguns dos seus aspectos que interferem diretamente na vida das universidades públicas brasileiras. O projeto de universidade mais cuidadosamente formulado na história do país foi o da Universidade de São Paulo, amadurecido entre os anos 20 e 30 por liberais ilus- 
trados, preocupados com a consolidação da República num país de tradições rasas e em cuja cena política dominavam as oligarquias, vistas pelos liberais paulistas como lastro inútil e indesejável, responsável pela lentidão do ingresso na modernidade política. É interessante notar que a decantada "formação das elites", bandeira ostensiva do grupo que então pensava a futura universidade, aparecia como algo indissoluvelmente ligado ao caráter público da universidade, sendo visto como a maneira de superar os vícios que proliferavam no cenário político.

As novas elites, resultantes de um processo de formação cultural concebido a partir de horizontes amplos e desvinculados dos limites profissionalizantes, descomprometidas com as motivações sócio-econômicas que viabilizavam a reprodução da política oligárquica, deveriam fazer frutificar uma mentalidade propícia ao cultivo dos mais elevados valores culturais e políticos, que se concebia naturalmente como sendo aqueles vinculados ao ideário liberal.

Qualquer que seja o juízo que se faça acerca da ideologia subjacente à proposta, há de se convir, mormente num olhar retrospectivo, que se pensava numa convergência entre a universidade pública, a coisa pública e o homem público. Deliberadamente ou não, e mesmo com graus variáveis de autenticidade, o liberalismo ilustrado da época, ao menos no contexto da campanha pela universidade, conferiu ao público o estatuto de um valor, concebendo a universidade pública como o lugar apropriado para a discussão e a construção de valores. Ainda que se possa ver aí um certo direcionamento, definido a partir de posições ideológicas determinadas, é possível perceber, ao menos residualmente, uma iniciativa de promoção do público e do institucional a condições indispensáveis à consecução de finalidades consideradas positivas para a sociedade em vias de organização.

Este papel preponderante do público na organização da sociedade entraria depois em declínio: sua breve revitalização nos anos imediatamente anteriores ao golpe militar de 64 poderia ser vista como a melhora que por vezes antecede a morte do doente. Atualmente vivemos a ocupação do espaço público pelos meios de manipulação e mistificação da opinião, meios voltados para a finalidade de diluir este espaço. $\mathrm{O}$ fato de que o governo desenvolve um processo acelerado de isentar-se de suas responsabilidades públicas é testemunho eloqüente desta perda. A universidade sofre as conseqüências deste processo. Da valorização da iniciativa pública de projetar uma universidade - que o liberalismo ilustrado considerava como dever cívico - à valorização da iniciativa privada no ensino por parte da ditadura e do liberalismo tecnocrático, foi percorrido um caminho em que a brevidade cronológica contrasta com a intensidade da degradação.

É claro que, no caso do ensino superior, as ameaças que pesam sobre a universidade pública são os sintomas evidentes da deterioração da concepção de universidade. A prova disto é que pouco se atenta para determinadas caracte- 
rísticas e funções que dificilmente seriam mantidas fora da universidade pública, e que incidem diretamente no ensino, na pesquisa e na vida cultural do país. A dedicação exclusiva ao ensino e à pesquisa que, como já mencionamos, é fator preponderante no aprimoramento das atividades nas melhores universidades públicas, não foi pensada pelos seus idealizadores como uma medida técnicoadministrativa, visando a maior eficiência do trabalho universitário. Ela foi uma opção política decisiva no processo de qualificação da atividade acadêmica. Significa um investimento direto na formação constante do docente-pesquisador, a partir de uma visão ampla da relação entre ensino e pesquisa, cuja indissociabilidade está no núcleo do ideário de excelência acadêmica.

O fato de a pesquisa básica ter se desenvolvido graças a esse fator mostra a vinculação intrínseca deste regime de trabalho com uma idéia de universidade que se pauta pela recusa de entender o ensino e a pesquisa como serviço e mercadoria. A produtividade acadêmica, em nível didático ou da pesquisa, não se vincula a produtos ou à venda de serviços. E foi precisamente graças a este distanciamento que a universidade pôde contribuir para a solução de problemas nos mais variados aspectos da organização social: porque tais soluções surgiram a partir da liberdade de pesquisa e de uma visão de maior alcance das relações entre a ciência e o desenvolvimento tecnológico. São as mediações que resguardam a universidade pública da subordinação imediata ao mercado e os fatores que permitem a qualidade de sua contribuição à sociedade. É a independência nos processos de investigação e de debate que garante o desenvolvimento da produção, da transmissão e da aplicação do saber. Aqueles que assimilam tais características ao desinteresse e à "torre de marfim" demonstram desconhecimento das especificidades do trabalho universitário, e de seu alcance históricosocial.

A autonomia da universidade, requisito para a realização da idéia de universalidade, não significa que a instituição abstrai o contexto social no qual se insere. A independência, como distanciamento crítico, possibilita, ao contrário, que este contexto possa ser pensado como um pólo de relação que não se confunde com qualquer conjunto de interesses particulares, sejam eles mercadológicos, empresariais ou políticos. A abstração ocorreria precisamente se a universidade servisse imediatamente a determinados interesses, com exclusão de todos os outros que atravessam uma sociedade complexa e contraditória.

O investimento necessário ao desenvolvimento da pesquisa básica e a manutenção da condição indispensável da dedicação exclusiva exigem o comprometimento do Estado. As finalidades próprias de uma organização empresarial não suportariam tal compromisso. Assim, há de se convir que as atividades fundamentais da universidade estão intrinsecamente vinculadas ao caráter de instituição pública. A quem serve a pesquisa básica? Do ponto de vista de interesses imediatos, a ninguém. Do ponto de vista de sua inserção num 
projeto histórico-político emancipatório de dimensões amplas, serve a todos, serve à nação. Por desprezarem esta mediação e esta diferença, muitos vêem na pesquisa básica e na dedicação exclusiva um ônus pesado e inútil. Parte dos que pensam assim o fazem por ignorância; outros, entretanto, representam interesses político-econômicos que seriam mais bem atendidos por um projeto contrário ao desenvolvimento social e à emancipação. E, lamentavelmente, entre estes últimos encontram-se aqueles que estão em posição de interferir nos destinos da universidade pública.

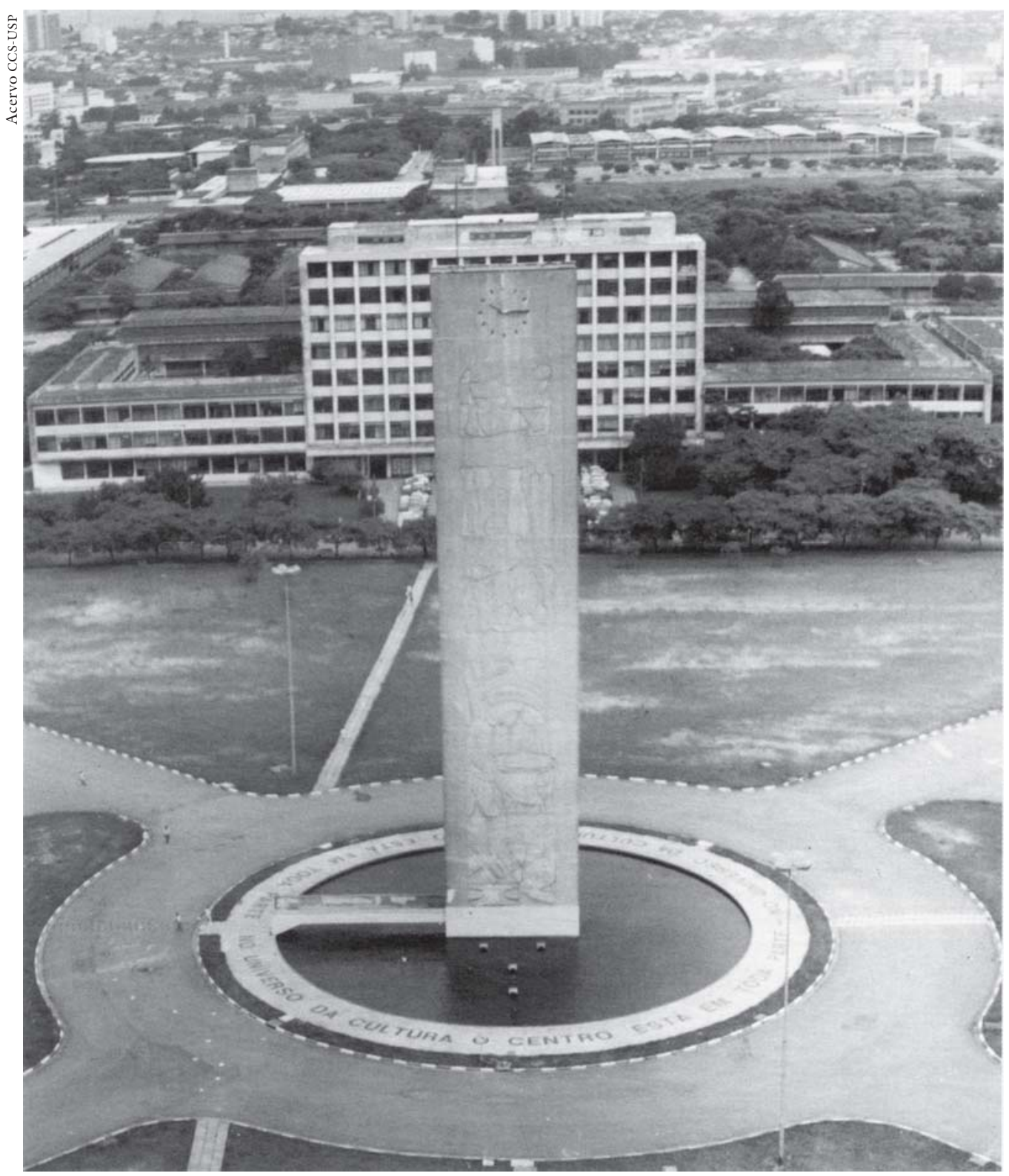

O projeto de universidade mais bem formulado na história do pais foi o da USP, amadurecido entre os anos 20 e 30 


\section{Universidade pública e cultura}

É preciso considerar também os aspectos da relação entre universidade e cultura. Quais são as condições de preservação, de apropriação da cultura, e de reflexão crítica sobre ela? Mesmo um diagnóstico superficial da época em que vivemos é suficiente para mostrar a precariedade destas condições. $\mathrm{O}$ ritmo do tempo histórico, marcado pelo círculo perverso entre produção e consumo até mesmo daquilo que entraria na categoria dos "bens culturais": o imediatismo e o caráter efềmero e disperso dos interesses que os indivíduos são encorajados a cultivar, a fragmentação e a distorção da informação, a mercantilização extremada dos meios de comunicação, a prioridade da realização de anseios impostos por um processo de racionalidade ideologicamente comprometido com critérios definidos de forma unilateral, estão entre os fatores que tendem a desagregar a identidade cultural.

Os acessos ao mundo da cultura são cada vez mais intensamente submetidos a mecanismos alienantes, sem que o Estado assuma qualquer medida no sentido de garantir o acesso efetivamente democrático: pelo contrário, os poderes públicos se fazem cúmplices dos oligopólios midiáticos. A universidade pública é a única instância em que se pode resistir, de alguma maneira e por mais algum tempo, talvez, a este processo que traz na sua própria dinâmica um objetivo destruidor. A universidade pública é a instituição em que a cultura pode ser considerada sem as regras do mercado e sem os critérios de utilidade e oportunidade socialmente introjetados a partir da racionalidade midiática.

Esta é a razão pela qual se critica a universidade por abrigar tantas coisas “inúteis", tais como a Filosofia, as Letras Clássicas, os Estudos Literários etc. Mesmo as áreas de Humanidades que se constituíram como ciências na modernidade - como Sociologia, Antropologia ou História -, entram também de alguma maneira no rol dos ornamentos supérfluos, a menos que se prestem diretamente a se transformarem em instrumentos de poder tecnocrático. $\mathrm{O}$ patrimônio cultural é redefinido e reapropriado a partir de critérios extrínsecos. Para que a disseminação pública da cultura fuja a estas determinações pragmáticas e economicistas é necessário um espaço público de preservação, de apropriação e de reflexão. As atividades que aí se desenvolvam não se podem subordinar a critérios da expectativa de retorno de investimento. Por isto a universidade como instituição pública pode assumir a função de garantir o efetivo caráter público de que em princípio se revestem os bens de cultura historicamente legados ao presente, à medida em que estes não se apresentem como produtos que as organizações comerciais de ensino possam vender no mercado.

Faz parte da autonomia da universidade pública esta relação intrínseca com a cultura, que permite que o acesso não seja filtrado por dispositivos discriminadores montados em outras instâncias da vida social. É esta publicidade da 
cultura, que só na instituição pública pode se articular em algum grau, que garante o conhecimento, a apropriação intelectual, a reflexão, a crítica e o debate.

E isto significa democratização, atendimento ao direito que tem o cidadão de participar da cultura.

Franklin Leopoldo e Silva é professor da Faculdade de Filosofia, Letras e Ciências Humanas da USP. 